\title{
Un barrio marginado no es un barrio marginal. A propósito de Nazaret (Valencia)
}

\author{
A Marginalized Neighbourhood is not a Marginal \\ Neighbourhood. Case Study Nazaret (Valencia)
}

\author{
Josepa Cucó i Giner \\ Universidad de Valencia (España) \\ josepa.cuco@uv.es
}

\section{RESUMEN}

Este texto nos sitúa en Nazaret, un barrio periférico del water front de Valencia al que se observa desde tres perspectivas complementarias, representadas respectivamente por la mirada sincrónica de su actual estructura socioespacial; la contextualización diacrónica y procesual de los cambios que experimenta en el transcurso del último siglo; y el abordaje de las percepciones e imágenes que caracterizan al barrio así como los rasgos, actividad e incidencia de su tejido asociativo. El análisis focaliza el comportamiento de un conjunto de factores interconectados entre los que destacan los impactos del puerto y de las políticas urbanas, su composición socioeconómica, la consistencia de su tejido asociativo y la relación que mantiene con la administración. Mientras los tres primeros ítems favorecen la extensión de la precariedad y la vulnerabilidad social, impeliendo al barrio hacia la marginación y la exclusión, los segundos, encabezados por el prolongado dinamismo de su asociación de vecinos y el enfrentamiento que mantiene con el consistorio municipal, contrarrestan los efectos negativos de barrio, obstaculizando el tránsito de barrio marginado a barrio marginal.

Palabras clave: Frente marítimo; Barrios periféricos; Efectos de barrio; Precarización; Marginación; Movimientos urbanos.

\section{SUMMARY}

This article takes us to Nazaret, an outlying district on Valencia's waterfront which we consider from three complementary perspectives: the synchronic vision of its current socio-spatial structure, the diachronic and processual contextualization of the changes it has undergone in the last century, and the perceptions and images which characterize the neighbourhood, together with the features, activity and incidence of its associative fabric. The analysis focuses on the behaviour of a set of interconnected factors, including the impact of the port and urban development policy, its socioeconomic make-up, the consistency of its associative fabric and its relations with government. Whereas the first three have promoted the spread of social vulnerability and precariousness, propelling the neighbourhood towards marginalization and exclusion, the latter, led by the ongoing dynamism of its residents' association and its confrontation with the local council, is counteracting the negative effects on the neighbourhood, helping to stop a marginalized neighbourhood from becoming a marginal one.

Key words: Waterfront; Outlying Districts; Neighbourhood Effects; Precariousness; Marginalization; Urban Movements. 
La película del director de cine español Alberto Morais, "Los chicos del puerto" ${ }^{1}$, utiliza la experiencia de tres niños de Nazaret, un barrio periférico de Valencia, para dibujar un retrato del abandono social, familiar, económico y político que viven actualmente los más desfavorecidos de la sociedad. En una entrevista difundida por Internet explicaba que se trata de "un barrio muy duro y aislado". El cineasta lo conoce de primera mano. Durante muchos años su padre ejerció allí como médico, colaborando también con los equipos sociales de colectivos del barrio. Estaba al tanto de sus problemas y de lo que para mucha gente significaba vivir en ese lugar. "Es un barrio muy marginado, no marginal", afirma.

Las palabras del cineasta articulan los contenidos de este trabajo y también le dan título. El mensaje que transmiten puede en principio parecer paradójico. ¿Cómo es posible que un barrio marginado, al que se caracteriza como duro y aislado, no sea marginal? ¿Qué procesos y hechos se esconden tras este aparente juego de palabras, cómo interpretarlas? Sin pretender emular al diccionario de la RAE diré que el término marginal es indicativo de un estado de cosas, el de una persona o grupo que se encuentra fuera de los márgenes de la sociedad. Por su parte, el término marginado añade un matiz importante: que la no integración es resultado de un proceso del que no sólo puede buscarse un origen o un causante ${ }^{2}$ sino que puede revertirse de manera parcial o total o, por el contrario, agravarse y cronificarse.

Cuando desde una perspectiva dinámica se observa dicho proceso en el ámbito urbano resulta imprescindible sacar a colación ciertas cuestiones. Unas tienen carácter general y afectan a la configuración del nuevo orden espacial de las ciudades; otras priorizan una perspectiva micro para focalizar las trasformaciones que experimentan sus barrios (Marcuse y Van Kempen 2000: 3; Murie y Musterd 2004; Musterd et al. 2006; Musterd 2008, entre otros). En relación a los primeros, se ha señalado reiteradamente que los desarrollos de la globalización neoliberal han generado nuevas inseguridades sociales que tienden a concentrarse en determinados enclaves territoriales, donde se experimentan con más intensidad los efectos de la reestructuración de la economía, los recortes del Estado de bienestar y la negación del acceso a determinados derechos ciudadanos. Se afianza de este modo la dimensión espacial de la exclusión so$\mathrm{cial}^{3}$, que supone un nueva vuelta de tuerca en los procesos de segmentación

\footnotetext{
${ }^{1}$ La película fue estrenada en el Festival Internacional de Cine de Toronto de 2013.

${ }^{2}$ La RAE define marginal como "una persona o grupo que vive o actúa, de modo voluntario o forzoso, fuera de las normas sociales comúnmente admitidas". Del vocablo marginado/da señala que referido a una persona o de un grupo significa "no integrado en la sociedad"; no obstante, al referirse a la raíz del participio del verbo marginar la RAE añade ciertos aspectos que aquí interesan: que alguien tiene la capacidad de "preterir a alguien, ponerlo o dejarlo al margen de alguna actividad", de "prescindir o hacer caso omiso de alguien", o de "poner o dejar a una persona o grupo en condiciones sociales, políticas o legales de inferioridad".

${ }^{3}$ Martínez Monje destaca que la exclusión espacial "es tanto el resultado como el proceso a lo largo del tiempo por el que una pluralidad de personas y grupos sociales que habitan un barrio restringen a los demás habitantes o tienen propiamente un acceso restringido (en disponibilidad, continuidad, precio, accesibilidad y conocimiento) a las condiciones de vida, a los equipamientos públicos y servicios y a la participación y gestión local, necesarios socialmente y estatuidos como derechos civiles, políticos y sociales de ciudadanía para el desarrollo de una vida integrada en una comunidad y en el área territorial (local, metropolitana, provincial, regional o estatal) que se tome de referencia" (2006: 99; citado por Cal y Martínez 2009).
} 
socioespacial, algunas de cuyas manifestaciones son la aceleración de la concentración en determinados barrios habitados por pobres, inmigrantes y minorías étnicas; la expansión y consolidación de las underclass y de una economía informal; el crecimiento en paralelo de áreas gentrificadas y áreas de pobreza; el avance de la desafección política, el debilitamiento de las redes de solidaridad y de acción colectiva en los barrios más desfavorecidos (Cal y Martínez 2009: 879; Blanco, Fleury y Subirats 2012: 13). No obstante, aunque la segregación sociourbana se ha incrementado de manera importante en el conjunto occidental, adopta formas diferentes en las ciudades europeas y norteamericanas. Como destaca Loïc Wacquant (2001, 2007), hoy por hoy, las periferias urbanas europeas son espacios de diversidad, aunque es bastante habitual que los medios de comunicación presenten algunas de ellas como áreas guetificadas e internamente homogéneas, en especial cuando abunda la población inmigrante. Como argumenta el referido autor, una de las razones por las que las banlieues francesas son mucho menos terribles y opresivas que los guetos norteamericanos radica en la ideología republicana, que proclama una ciudadanía unitaria y una participación abierta en la comunidad nacional.

La disparidad de resultados de los mencionados cambios no sólo guarda una estrecha relación con las estructuras socioeconómicas y los regímenes de bienestar específicos de cada lugar (estado, región, ciudad) sino que depende de manera muy notable de los rasgos, significados y dinámicas que caracterizan y afectan a cada barrio particular (Kearns y Parkinson 2001; Díaz de Orueta 2012). Es más, en lo que a las situaciones de exclusión social concierne, el barrio exhibe una naturaleza propia (Cal y Martínez, 2009: 880). Como escenario microsociológico donde se hacen efectivas las nuevas desigualdades sociales y la nueva pobreza urbana, el barrio ejerce importantes efectos sobre la exclusión social: desde los controvertidos 'efectos de barrio' (neighbourbood effects $)^{4}$, que inciden negativamente en las posibilidades de sus habitantes, hasta el trabajo transformador y proactivo desarrollado por activistas y asociaciones del barrio para revertir el abandono y la decadencia de su zona y (re)conquistar parcialmente la calidad de vida y del medio ambiente (Anguelovski 2013; Cucó 2014).

El barrio de Nazaret representa un buen ejemplo de esta última tendencia según la cual la acción colectiva —y esta es precisamente la hipótesis que defiendo-, que

${ }^{4} \mathrm{El}$ concepto hace referencia a dos procesos paralelos: se dice, por un lado, que existe efecto de barrio "cuando el hecho de vivir en un barrio dado provoca un cambio neto en las conductas de los individuos. Estos efectos pueden deberse a la influencia de los grupos sociales, a los recursos del barrio o a la percepción que los individuos tienen de su barrio. Pueden ser positivos o negativos (efectos de los 'beaux quartiers' distintos a los efectos de los 'quartiers défavorisés' " (Houart y Annerel 2011: 1). Pueden referirse también a los efectos negativos extra que puede tener sobre el barrio y sus habitantes la aplicación de políticas públicas selectivas para reducir la marginalidad social. Detectados por los estudios de Wilson (1987) y Massey y Denton (1993) sobre los guetos negros de Norteamérica, dichos efectos han sido sistematizados recientemente por Bauder (2002), Buck (2001) y Van Ham et al. (2012), entre otros. Por su parte, Blanco y Subirats (2011: 340-341) diferencian entre dos grandes tipos de 'efectos de barrio': el primero está relacionado con el ambiente social y la composición social del barrio; el segundo concierne a la accesibilidad territorial a distintos bienes (como el trabajo, el ocio, el espacio público, los equipamientos y los servicios públicos de calidad). Aunque ha gozado de gran predicamento a una y otra orilla del Atlántico, este concepto también ha sido objeto de abundantes críticas y escrutinios escépticos (Vallet 2005; Wacquant 2007; Musterd 2008; Houart y Annerel 2011). 
es en su caso resultado de la particular interacción entre la densidad y dinamismo del tejido asociativo, el impacto de las políticas urbanas y la relación con la Administración, ha obstaculizado el tránsito de barrio marginado a barrio marginal. Con el objeto de evidenciar este proceso articulo el trabajo en tres apartados: el primero presenta a modo de foto-fija el panorama del Nazaret actual; el segundo contextualiza diacrónica y procesualmente las transformaciones que ha experimentado a lo largo de los últimos cien años; el tercero aborda las percepciones existentes sobre el barrio así como los rasgos, actividad e incidencia de su tejido asociativo5.

\section{EL ESTADO DE LA CUESTIÓN: UNA FOTO (FIJA) DEL NAZARET ACTUAL}

En enero de 2014 participé en una visita de grupo por las fronteras del barrio. Teníamos como guía al portavoz de la Associació de Veïns $i$ Veïnes de Natzaret que nos acompañó durante más de tres horas a lo largo de un trayecto que alimentó una congoja e indignación crecientes. Aislamiento, malos olores y ruido son algunos de los conceptos que resumen a nivel físico su situación actual. El itinerario comenzaba en el puente de Astilleros, que atraviesa el antiguo cauce del río, cerca de su desembocadura, uniendo el barrio con el puerto. En esta frontera norte, Nazaret no disfruta de ninguno de los beneficios del cercano Jardín del Turia ${ }^{6}$, que finaliza abruptamente al poco de superar el tramo de la Ciudad de las Artes y las Ciencias (CAC) en dirección al mar; más bien ocurre lo contrario, una pestilencia constante emana de las aguas de un río hace tiempo desviado y desaconseja adentrarse por el descuidado paseo, en cuyo recorrido final se divisaba en aquel momento la impresionante mole de los depósitos de una fábrica de aceite ${ }^{7}$ abandonada.

Giramos entonces hacia el este, hacia donde se supone que está el mar. Pero un elevado muro recorre toda la fachada oriental del barrio e impide verlo. Un rumor sordo y constante proveniente del denso tráfico de vehículos pesados que transita al otro lado de la tapia, por la carretera del acceso sur del puerto, invisible a nuestros ojos, reemplaza el batir de las olas. De vez en cuando, los pitidos que emiten las grúas en movimiento emulan los graznidos de las gaviotas. Tal y como escribió hace poco el periodista Vicent Molins, "en el frente marino de Nazaret no hay playa, aunque todo el tiempo está presente. Las casas miran hacia ella, las antiguas garitas están frente a ella, los muros hablan de ella con los versos de Kavafis: 'Aquí que me detenga. Que

\footnotetext{
${ }^{5}$ Señalar por último que este trabajo se alimenta de las fuentes teóricas y de los frutos una investigación realizada en el marco de un proyecto I+D (CSO2009-10715) sobre la ciudad de Valencia, algunos de cuyos resultados se reúnen dos publicaciones colectivas recientes [Cucó (ed.) 2013a; Cucó (dir.) 2013b]. Aun reivindicando la continuidad con el citado estudio, lo que destaca en el proceso de investigación sobre Nazaret es que se realiza esta vez en solitario, combinando las técnicas etnográficas (observación participante y entrevistas en profundidad, tres en total) con el recurso a fuentes documentales.

${ }^{6}$ El Jardín del Turia es resultado del desvío del río Turia y el ulterior ajardinamiento del antiguo cauce a su paso por Valencia.

${ }^{7}$ La fábrica fue derruida a mediados del 2014. Era una vieja reivindicación de los vecinos y vecinas de Nazaret que por fin se hizo realidad, aunque aún queda pendiente la segunda parte de su demanda: que el solar resultante de la demolición revierta en el barrio debidamente descontaminado.
} 
también yo contemple un poco la naturaleza. Azul esplendoroso de un mar de la mañana y de un cielo sin nubes, y una ribera amarilla: todo hermosamente y con plenitud iluminado'".

Por el oeste, Nazaret también respira incomunicación y encierro: torres construidas a base de contenedores portuarios ocupan las antiguas huertas y, junto a ellas, el yermo vacío de un proyecto fallido, el de la zona de actividades logísticas (ZAL) del puerto. Unos cientos de metros más allá discurren las vías del tren que por este tramo permanecen descubiertas, una barrera a la que se suma la autopista que lleva a la Devesa del Saler, con su tránsito incansable.

Para presentar la estructura sociourbana del barrio partiré del panorama que presentaba a principios de años noventa del pasado siglo, momento en que se publica un estudio realizado por el Grupo de Intervención Comunitaria de Nazaret (GRICN

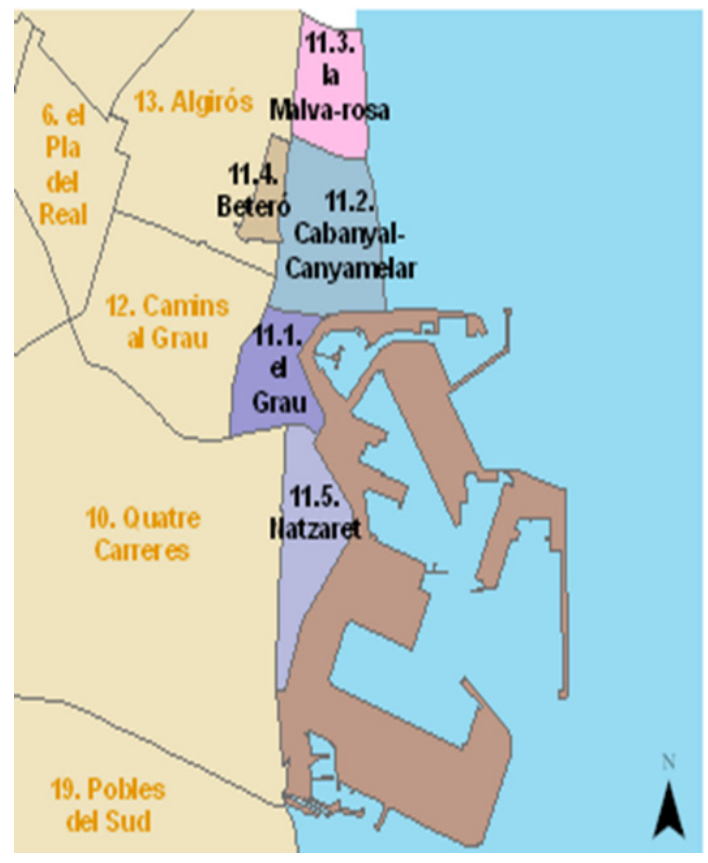

IMAGEN 1.-Los cinco barrios del distrito de los Poblados Marítimos de Valencia; de norte a sur: Malva-rosa, Beteró, Cabanyal-Canyamelar, el Grao y Nazaret. El espacio litoral sombreado marrón corresponde al ocupado por el puerto, que barre el acceso al mar de los barrios del Grau y Nazaret. 1992), que ponía cifras y datos a la precariedad. Por un lado, en comparación con el conjunto de Valencia, la situación laboral de los vecinos de Nazaret destacaba por una mayor proporción de parados, el elevado porcentaje de obreros (más de la mitad de los cabezas de familia lo eran en ese momento) y la importancia relativa de trabajadores incluidos en la categoría de 'inclasificables' (13\%), que incluía a chatarreros, recogedores de papel y otras ocupaciones marginales. Su población se distinguía también por su bajo nivel de estudios: en comparación con la media de la ciudad existía una mayor proporción de analfabetos (10\%) y personas sin estudios (más del 40\%), siendo muy pocas las personas con estudios superiores. Por su parte, la estructura urbana se caracterizaba por la abundancia de viviendas de mala calidad, la falta de infraestructuras (agua potable, alcantarillado, alumbrado, asfaltado de calles, mercados, servicios, etc.) y por una amplia utilización de su suelo para uso industrial ${ }^{9}$. Como consecuencia de tales deficiencias,

\footnotetext{
${ }^{8}$ Texto de Vicent Molins en el periódico digital culturplaza.com. del 21/02/2015, http:// www.valenciaplaza.com/ver/150111/bienvenidos-a-nazaret-patio-trasero.html. El poema de Kavafis está escrito, junto a otros textos y dibujos, en el muro de separación.

${ }^{9}$ Como afirma el estudio, hace veinticinco años prácticamente todo Nazaret estaba "rodeado por industrias o almacenes o depósitos subsidiarios del Puerto (ARLESA, TEPSA, CAMPSA, contenedores, troncos)" (GRICN 1992: 41).
} 
una importante proporción de vecinos se quejaba de problemas higiénicos, siendo los más citados "los malos olores, el ruido, el encharcamiento de las calles y la abundancia de ratas" (GRICN 1992: 41). A estas carencias se sumaban numerosos problemas sociales de entre los que el estudio destacaba - por este orden - la drogadicción, las conflictivas relaciones entre gitanos y payos y la falta de "un espíritu de barrio". Veinticinco años después algunas de estas cuestiones ya se han resuelto, pero la balanza continúa decantándose del lado de lo precario.

Nazaret ha cambiado, pero Valencia también. Durante ese lapso de tiempo diversos procesos han sacudido al conjunto de la ciudad. Como destacan Torres y García (2013), la política urbana aplicada por el gobierno municipal ha impactado sobre la trama sociourbana preexistente modificándola en un doble sentido: propiciando el aumento de la desigualdad socioespacial, al arrinconar las necesidades de los barrios populares y alentar al mismo tiempo el surgimiento de nuevos barrios de medio y alto estanding; favoreciendo la extensión de la precariedad, al no poner los medios para corregir las tendencias derivadas del impacto sobre la población de una serie de factores entre los que se incluyen los de carácter estructural y sociodemográfico.

Algunos barrios, entre los que destacan los del distrito de los Poblados Marítimos y sobre todo Nazaret, acumulan algunos de los indicadores que inclinan la balanza del lado de la precarización y la vulnerabilidad (Alguacil, Camacho y Hernández 2014): vecindarios con las rentas más bajas ${ }^{10}$, envejecimiento poblacional, unos niveles formativos bajos ${ }^{11}$ y una inmigración no comunitaria notable ${ }^{12}$. Para el año 2012, según el Padrón municipal, los datos de Nazaret al respecto se concretan como sigue: primero, el índice de vejez del barrio alcanza el 22,9\%, casi cinco puntos por encima de la media del conjunto de Valencia. Segundo, Nazaret sobresale tanto por unos porcentajes relativamente elevados de personas analfabetas $(5,5 \%)$ y sin estudios $(16,6 \%)$, cifras que superan en 4 y 7 puntos respectivamente la media de la ciudad, como por la escasa población con estudios superiores (4,3\%), porcentaje que es significativamente inferior a la media de Valencia (19,3\%). Tercero, Nazaret presenta unos porcentajes de inmigrantes que suponen un $19,3 \%$ de la población total, cifra que supera casi cinco puntos porcentuales la media de la ciudad. En lo que a este último ítem respecta, según Torres y García (2013), la inserción de estos nuevos vecinos y vecinas no hace sino

${ }^{10}$ La renta está muy desigualmente distribuida en los distintos barrios de Valencia, siendo mayoría aquellos donde predominan las rentas inferiores. Estos barrios coinciden con los históricamente más pobres, que han configurado las áreas de precariedad de la ciudad, entre los que se sitúa Nazaret y el conjunto de los Poblados Marítimos (Torres y García 2013).

${ }^{11}$ Aunque ha mejorado en el trascurso de las últimas décadas, el nivel de estudios de los residentes de Nazaret continúa presentando unos rasgos que apuntan hacia la vulnerabilidad social. Como es sabido, los bajos niveles formativos reproducen las desigualdades sociales y dificultan enormemente los procesos de movilidad social ascendente.

12 Valencia experimentó un crecimiento notable la población inmigrante durante la primera década del presente siglo, pasando de representar de un 1,5\% a un 14,8\% del total (Torres 2011: 182). A resultas de este proceso, el vecindario de la ciudad no sólo es ahora mucho más heterogéneo, sino que en él los recién llegados tienden a engrosar los sectores socioeconómicamente más frágiles. Los efectos de tales procesos (aumento de las tasas de inmigración e incremento de la vulnerabilidad social) se han distribuido desigualmente en la geografía urbana, siendo en las zonas periféricas donde más se acrecientan ambos. Como barrio de acogida, Nazaret se sitúa de lleno en la referida tendencia. 
agravar la situación de unos barrios que ya presentaban antes importantes insuficiencias a nivel de equipamientos, servicios públicos y, en algunos casos, de accesibilidad. En Nazaret esta problemática se agranda por la presencia de una numerosa población gitana asentada desde antiguo, cuya consideración ha ido cambiando a peor con el transcurso del tiempo dando lugar a importantes tensiones y conflictos. Como comentaban dos líderes del movimiento vecinal, hace treinta o cuarenta años, entre payos y gitanos

había una cierta relación, digamos, de coexistencia pacífica o guerra fría... En los tiempos que nosotros no hemos conocido no había, yo no tengo constancia, que hubieran habido conflictos. No, no, no, el conflicto es a partir del año 73 por el tema del narcotráfico y un poco antes por el tema de la delincuencia (Entrevista a R.A y J.M.) ${ }^{13}$.

Finalmente, en Nazaret concurren además ciertos problemas específicos, ya mencionados antes, que acrecientan la tendencia hacia la vulnerabilidad. Por un lado, un notable malestar vecinal provocado por el aislamiento físico, el ruido, la contaminación y los malos olores originados por la actividad portuaria y por las aguas pútridas que invaden el tramo final del antiguo cauce del río que, en claro contraste con la profunda transformación ocurrida en su recorrido por buena parte de la ciudad, no ha sufrido aquí remodelación alguna. Por otro, el poso que en el imaginario de los habitantes de Valencia han dejado los problemas de drogas y delincuencia presentes en las últimas décadas tanto en Nazaret como en el conjunto de los barrios marítimos, que se asocian con frecuencia a la presencia de población gitana y que han contribuido a dibujar los contornos de un estigma que no sólo marca a su vecindario, sino que introduce la división y el conflicto en su seno. Por último, la política de grandes eventos desarrollada por los gobiernos municipal y autonómico en la primera década de los años dos mil no ha hecho sino lanzar más leña al fuego. Su impacto sobre el barrio es claramente negativo. En una entrevista concedida a un diario digital en 2008, el portavoz de la Associació de Veïns $i$ Veïnes de Natzaret criticaba abiertamente esas grandes celebraciones, denunciando la repercusión sobre el barrio del circuito de Fórmula 1. No es por azar que el día inaugural de dicho Gran Premio fuera esta asociación, junto con el resto de organizaciones vecinales de los Poblados Marítimos y el colectivo ecologista Fòrmula Verda, las únicas voces que protestaran abiertamente en su contra:

Es la gran excusa para el márquetin y el lucimiento de los políticos. Se considera que los "grandes eventos" nos aumentan la autoestima aunque las cosas no funcionen en la vida cotidiana. En el caso de Valencia las grandes empresas han descubierto el mar como negocio: Copa del América, Fórmula 1, PAI del Grao, prolongación de Blasco Ibáñez. Son proyectos que forman parte de un modelo eminentemente especulativo... (En Nazaret la Fórmula 1 provoca) muchas molestias y mucho ruido. Rodeado de infraestructuras ferroviarias y portuarias, Nazaret ya se encontraba aislado de Valencia, y el circuito (de Fórmula 1) ha ahondado en este problema. Desde junio (las carreras se celebraron en agosto) ha sido cada vez más difícil acceder a nuestro barrio ${ }^{14}$.

\footnotetext{
${ }^{13}$ Texto traducido del valenciano original.

${ }^{14}$ Publicado en http://www.rebelion.org/noticia.php?id=73557 el 01/10/2008.
} 


\section{SIGUIENDO LAS HUELLAS DE UN CAMINO INVERSO}

Llegados a este punto cabe preguntarse cuándo comienza a gestarse este estado de cosas, si se trata de un proceso lineal o, por el contrario, cabe distinguir en él etapas de signo distinto. Situado en el presente, el presidente de la mencionada Associació de Veïns $i$ Veïnes nos habla de una dinámica de vaivén cuyo comienzo sitúa en las postrimerías del XIX:

Pero fíjate que sufrimos... un efecto hacia detrás cuando Nazaret había, digamos, experimentado un efecto de progreso anteriormente, porque de estar totalmente aislado, totalmente aislado a finales de siglo XIX y comienzo del XX, va, digamos, hubo un movimiento de unir Nazaret y Valencia. Por un lado, se juntaban los intereses de la gente acomodada que tenía aquí (tierras y casas) y tenía cargos en el ayuntamiento, ¿no? ... Y por otra parte el interés del puerto de conectar por esta parte del sur el puerto (Entrevista a R.A.).

En esta etapa que abarca desde finales del XIX hasta el primer tercio del XX, Nazaret experimenta un impulso que desde el presente se valora en positivo. En primer lugar, las vías de comunicación con la ciudad se multiplican y con ellas el barrio experimenta un salto hacia delante: en las postrimerías del XIX se construye el Camí Nou de Natzaret $^{15}$ que le une con Valencia siguiendo un trazado paralelo al río (por su margen izquierda) y poco después, a principios del siglo XX, se levanta un puente de hierro que comunica directamente el barrio con el puerto. En 1911 se abre al tráfico ferroviario el tramo Valencia-Nazaret por el que, además de viajeros, llegaban productos hortofrutícolas destinados a la exportación. La actividad y el comercio portuarios activan la vida económica de Nazaret; de su Estacioneta partía una nutrida red de carros que trasladaba la mercancía a los muelles del puerto a través de mencionado puente de hierro, muy transitado también por los trabajadores portuarios. Dos décadas más tarde, en 1931, se inaugurará un nuevo puente, el pont de les Drassanes (de Astilleros), por el que también pasará el tranvía.

Un segundo proceso contribuye a acrecentar el dinamismo socioeconómico de Nazaret. Como ocurre en tantos otros lugares de la península y de Europa, la extensión de un ocio veraniego comienza a colonizar sus playas y las de otros barrios marítimos de Valencia ${ }^{16}$. De este proceso serán protagonistas la burguesía y las clases populares de la ciudad, en cuyo frente litoral comienzan a desplegarse progresivamente, y con éxito, los variados signos que acompañan a la territorialidad veraniega de ambas (Raulin 2001: 86 y ss.): se construyen hermosas villas de veraneo, algún que otro balneario y en los meses de verano se multiplican los merenderos y las casetas de baño.

La guerra civil y la postguerra cambiarán la fisonomía y la estructura socioeconómica del conjunto de los barrios marítimos. A la destrucción causada por los bombardeos franquistas $^{17}$ se suma la producida por las devastadoras riadas de 1949 y 1957. Las consecuencias de estas catástrofes se combinan con otros tres procesos que modifi-

\footnotetext{
${ }^{15}$ Posteriormente conocido como Cami de les Moreres.

${ }^{16}$ En la Malva-rosa y en el Cabanyal, otros barrios marítimos más próximos a la ciudad, también experimentarán este proceso aunque con mayor intensidad (Cucó 2014).

17 Como recoge Santamarina (2009: 38ss.), el Puerto de Valencia y, en general, todas las zonas marítimas de la ciudad fueron sistemáticamente bombardeadas por las tropas fascistas tanto de manera aérea como naval.
} 


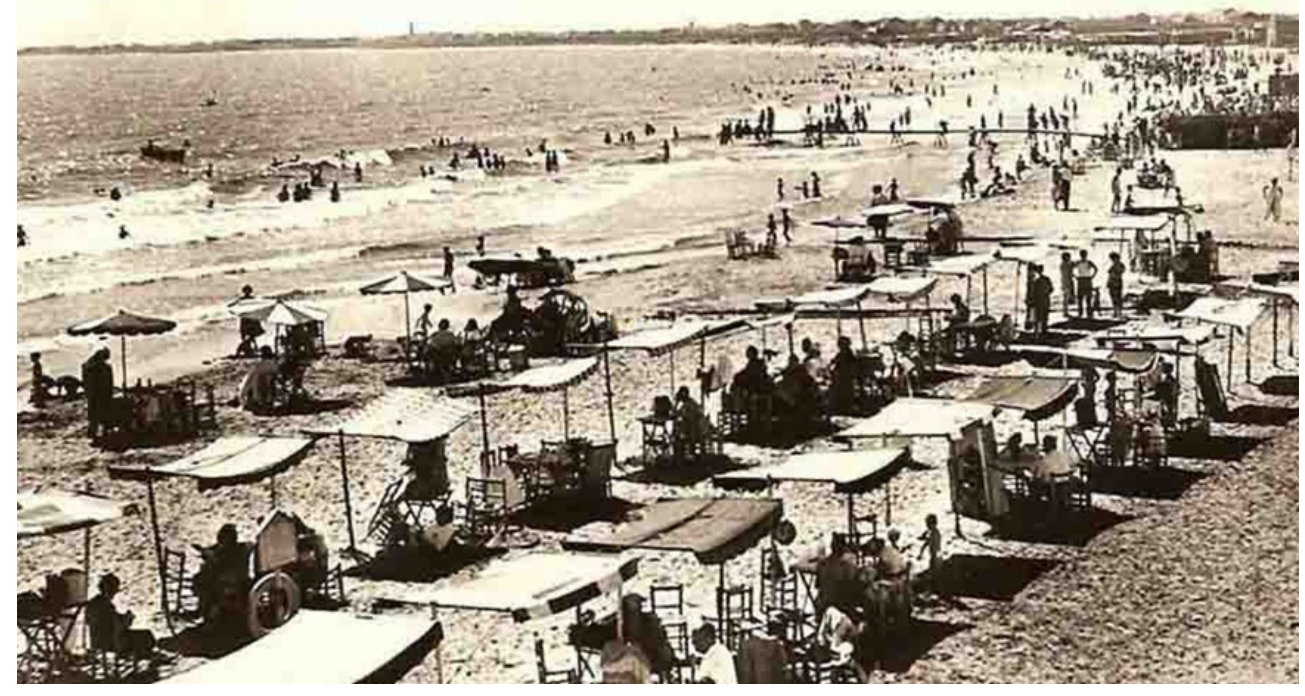

IMAGEN 2.- La playa de Nazaret a principios del siglo XX.

can de manera notable el espacio litoral urbano de Valencia: la expansión imparable del puerto, a la que se supedita la calidad y el crecimiento del hábitat; la industrialización de la zona, ya iniciada en el periodo anterior y que avanza ahora a marchas forzadas; la llegada de sucesivas oleadas de inmigrantes internos que ocupan viviendas precarias. El impacto conjunto de todo esto es especialmente notable en Natzaret. En efecto, durante la postguerra su población creció de manera notable debido al alud de inmigrados que construyeron chabolas y casas precarias junto a la línea de playa o incluso dentro del mismo cauce del río, hasta que se las llevó la riada de 1949. De este modo, algunos mallorquines pero sobre todo castellanos y andaluces se suman al núcleo de original de pobladores del barrio, integrado por labradores, pescadores, trabajadores portuarios y también algunas familias vinculadas a la explotación turística de la playa.

Por otro lado, el crecimiento incesante del puerto combinado con el desarrollismo sin freno de los años sesenta favorecen un proceso creciente de deterioro y aislamiento geográfico de Nazaret: nuevas infraestructuras (la autopista del Saler y un nuevo trazado ferroviario) acrecientan su incomunicación por el oeste; industrias contaminantes se asientan en el casco urbano; almacenes de troncos primero y contenedores después colonizan los terrenos de huerta; el río se convierte en desagüe de la ciudad de manera que en la siguiente década, la playa de Natzaret queda fuera de servicio por contaminación industrial y urbana. Completan el panorama unas infraestructuras barriales (acequias y vías del tren sin cubrir, contaminación por vertidos industriales, falta de alcantarillado, etc.) y unos servicios básicos inexistentes o, en todo caso, deficitarios. La acumulación de tanto quebranto hace exclamar a un vecino, 
¿tú te acuerdas del dictador aquel de México, Porfirio Díaz, que decía 'pobre México, tan lejos de Dios y tan cerca de Estados Unidos?', pues podríamos decir eso mismo, 'pobre Natzaret, tan lejos de la ciudad y tan cerca del puerto', quiero decir que ...a partir de esa fecha (años 60), que se hace la autopista del Saler, el tren... todas las actuaciones posteriores urbanísticas que se hacen van en el mismo sentido (Entrevista a J. M.).

Dos últimos acontecimientos resultan indicativos de la subalternidad creciente - en el sentido gramciano del término- de Nazaret. Uno viene dado por la edificación a principios de los cincuenta de las llamadas Casitas de Papel ${ }^{18}$, unos albergues provisionales que tras sucesivas oleadas de pobladores serán finalmente ocupadas por habitantes sin recursos, en su mayoría de etnia gitana, generando una bolsa de marginación y pobreza que alimenta la delincuencia, el tráfico de drogas y los problemas de convivencia barrial (Castaño 1995; GRICN 1992). El otro supone una enajenación de hondo calado que tendrá lugar a mediados de los años ochenta y que supondrá la total destrucción de su playa. Tan hermosa o más —a decir de algunos vecinosque la de la Malva-rosa, la playa le fue amputada a Nazaret en 1985 en aras de la construcción del acceso sur del puerto. De la añoranza por la playa perdida habla una vecina:

Antes aquí en Natzaret había una playa preciosa. Mucha gente de Valencia y de otras partes la prefería. También habían unos jardines muy bonitos, pero luego dicen que el progreso, el gobierno o la autonomía se la cargaron. Ahora todo es puerto (Entrevista recogida por el GRICN 1992: 117).

Pero la presión que sobre el barrio ejerce la tenaza del puerto no parece tener fin. Tras la ejecución del citado acceso sur, los terrenos de La Punta de San Silvestre - un valioso trozo de huerta declarada de protección especial en el PGOU de 1988 situado junto al mar, al oeste de Natzaret-, se recalifican como zona de actividades logísticas (ZAL) del puerto y se expropian de manera urgente ${ }^{19}$. En ambas enajenaciones, la de la playa y la huerta, se sigue el mismo proceso: primero se permite la degradación, luego, con este fait accompli, se expropia al vecindario del territorio en cuestión, ya sea del uso y disfrute de la playa o de la propiedad de las parcelas de huerta. De este modo se completa el círculo vicioso de la especulación, un proceso que - en opinión de un activista del barrio - es digno de formar parte del 'manual del especulador perfecto':

${ }^{18}$ La riada de 1949 provocó el arrasamiento de más de mil chabolas construidas dentro del cauce del río en las zonas de La Pechina, Campanar y Nazaret. Para alojar a sus habitantes se construyeron diversos barrios de casitas baratas entre las que se cuentan las Casitas de Papel de Nazaret, popularmente llamadas así por la frágil y modesta estructura de las viviendas, que fueron paulatinamente abandonadas por estos primeros moradores.

${ }^{19}$ La creación de este polígono industrial supuso la expropiación de terrenos y casas, afectó a unas trescientas familias y provocó un fuerte rechazo de los vecinos y vecinas que, agrupados en la asociación La Unificadora, entablaron una lucha desigual y abierta con la autoridad (municipal y portuaria). El documental $A$ tornallom da testimonio de la dureza y el drama de la lucha vecinal. Para mayor información consultar los trabajos de Cabrejas y García (1997), García (1999), y Romero y Francés (2012); también la web http://www.perlhorta.info/content/la-zal-1\%E2\%80\%99hortaval\%C3\%A8ncia-hist\%C3\%B2ria-\%E2\%80\%99una-trag\%C3\%A8diainacabada\#sthash.eN9GTvCG.dpuf. En la actualidad, más de quince años después de iniciarse el proceso, no sólo el espacio de la huerta expropiada y destruida sigue baldío, sino que los tribunales han declarado que aquella fue una expropiación ilegal. 
ahí al lado, en La Punta, que hay cien familias... gente mayor que ya no quería o no podía trabajar la tierra, los hijos no estaban muy encarados a trabajar la tierra y bueno, alquilan el campo para los contenedores (del puerto) y bueno, pues había una parte de gente que hizo esto, y es la estrategia del manual del especulador perfecto, primero degrada y como ya está... Con la playa fue lo mismo, la playa de Nazaret fue la salida de aguas negras de toda la ciudad y después de la fábrica de aceite también, con vertidos de grasa, al final, la playa estaba contaminada, evidentemente (Entrevista a J. M.).

Sin embargo, la injusticia y el olvido no caen en saco roto. En Nazaret, al igual que en tantos otros barrios de España, la lucha por una vida y unos entornos dignos alientan desde hace décadas un incansable movimiento vecinal. Nacida durante el tardofranquismo, a mediados de los años setenta, su asociación de vecinos tuvo que multiplicar su actividad para hacer frente a tanto problema acumulado. Desde ese momento, como veremos en el siguiente apartado, su acción organizada y constante no ha cesado (Colectivo de estudios por la autonomía obrera 1977; VV. AA. 1991; Cort 1995; Arqués 2011; Sánchis Pallarés 2011; Cucó 2014), como tampoco lo ha hecho la presión del puerto sobre el barrio, una opresión que siempre ha contado —es de rigor explicitarlo- con el beneplácito de los distintos gobiernos municipales.

\section{¿Y POR QUÉ NO ES MARGINAL? PERCEPCIONES DEL BARRIO Y DEL TEJIDO ASO- CIATIVO}

En este último apartado abordaré dos importantes cuestiones que modulan de forma contradictoria las percepciones y el devenir de Nazaret: el imaginario sobre el barrio y la acción vecinal. El primero parece jugar en su contra, el segundo a su favor. En efecto, los procesos anteriormente descritos (situación periférica, aislamiento y malas condiciones sociourbanas, droga y delincuencia), han contribuido a perfilar los contornos de un Nazaret marcado por la prevención social y el miedo. Se trata de un fenómeno común a muchas metrópolis que también ha hecho acto de presencia en Valencia y en sus barrios marítimos (en el Cabanyal y la Malva-rosa además de Nazaret). Desde finales de los ochenta la prensa valenciana se ha hecho repetidamente eco de los recelos que esas cuestiones despiertan entre los vecinos de la ciudad, del generalizado temor a que algún día la tensión estalle entrecruzada con racismo, de las reiteradas demandas y acciones del movimiento vecinal para solucionar tales problemas. Su impacto ha contribuido de manera importante a la estigmatización de estos barrios en los que indefectiblemente florecen los espacios del miedo. Como sabemos, la consolidación de tales espacios se encuentra estrechamente ligada a la prevención social y al estigma, que repelen a los potenciales visitantes foráneos e instauran la desconfianza en el seno del barrio, aumentando en paralelo la fragmentación social ${ }^{20}$. Los

\footnotetext{
${ }^{20}$ Como han puesto en evidencia diversos estudios (Davis 2001; Wacquant 2007, entre otros), el miedo se ha convertido en un factor de explicación decisivo de las dinámicas urbanas: no solo favorece la resignificación de los espacios, sino que con su uso político (las 'políticas del miedo'), se justifican y posibilitan determinadas actuaciones urbanísticas (Füredi 2007; Glassner 1999). El caso del valenciano barrio del Cabanyal, otro de los poblados marítimos de Valencia que padece desde hace décadas una degradación urbana inducida por parte del gobierno municipal (García y Ruiz 2013; Ruiz y García 2013; Cucó 2014) ilustra de manera paradigmática estos procesos.
} 
primeros no osan adentrarse en su territorio y, cuando lo hacen, aprietan a menudo el paso sumidos en una acuciante sensación de intranquilidad. Los vecinos, por su parte, dejan de cultivar con asiduidad la sociabilidad informal, de calle, para refugiarse cada vez más en la seguridad del hogar.

La degradación urbana y la vulnerabilidad social son también compañeros inseparables de los espacios del miedo. En lo que a Nazaret respecta hemos podido observar cómo la primera aparece como resultado de un proceso en el que pueden reconocerse distintas etapas y también los actores sociales que lo provocan y acrecientan: la autoridad portuaria y el gobierno municipal, cuya actuación se revela determinante para la entronización de Nazaret como barrio marginado y peligroso (VV. AA. 1991; GRICN 1992; García y Ruiz 2013; Ruiz y García 2013; Cucó 2014). Por su parte, en Nazaret, los perfiles de desigualdad urbana se combinan hasta conformar la trama específica de un microtapiz de precariedad social que ya estaba consolidado en los años noventa. En ese momento, la imagen idílica e idealizada de un barrio playero rodeado de huertas a donde acudían veraneantes y domingueros se ve definitivamente reemplazada por otra mucho menos placentera: la de un 'barrio-isla' sitiado por espacios inseguros e inmundicias. Los vecinos se sienten 'rodeados', conscientes de que la imagen del barrio que llega al exterior repele "como si tuviera el sida" (Colectivo IOE 1997). Una sensación de indefensión y pérdida se propaga en el seno del vecindario, mientras que entre los jóvenes se asienta un discurso de queja que enfatiza los problemas y carencias del barrio, tal y como puede observarse en los dos fragmentos siguientes. El primero recoge las impresiones de una vecina, los segundos reproducen las apreciaciones de un grupo de chicos:

Tengo mucha pena por las playas que nos han robado. Cada vez que pienso en ello me pongo a llorar. Esto ha sido cosa del Puerto. Como has vivido lo que es ir a la playa y tenerla cerca, delante de casa... Yo me volví acongojada el día que empezaron las obras. Dicen que el puerto da más categoría a la ciudad, da trabajo; pero es como si estuvieras encerrado, tienes una valla delante. Sí que hubo oposición, pero cuando las cosas están decididas de antemano, no en el barrio, sino por parte de los que mandan, aunque te muevas, poco puedes hacer. Ya está perdido (Entrevista a una mujer miembro del APA Vicente Hervás, GRICN, 1992: 173).

- Pero es que yo creo que Nazaret el defecto que tiene es que no tiene ná.

- Malvarrosa tiene la playa.

- Nosotros teníamos una playa muy, muy bonita.

— ¿Qué puedes decir de Nazaret si hablas con alguien de fuera?, ¿qué le dirías de Nazaret, algo importante que haya en Nazaret?

—iBares!, ¡bares!

— Mira, hace cuarenta años a Nazaret venía toda la gente de Valencia aquí, no tienes nada más que ver los chalets de Benimar, los pedazos de chalets que hay ahí ¿no?

-Ni luchando podíamos salvar la playa, así que empezaron a pudrirla y, como ya estaba podrida, pues qué más da (Entrevista a un grupo de jóvenes; Colectivo IOE 1997:15).

Vemos como en el Nazaret de finales del siglo XX concurren algunas dinámicas de exclusión social que también han sido detectadas en otros barrios periféricos de España ${ }^{21}$, en los que se localizan unos 'efectos de barrio' que contrastan con lo que

${ }^{21}$ Me refiero a los resultados de una investigación realizada por el equipo liderado por Blanco y Subirats (2012) en cinco barrios periféricos de otras tantas ciudades españolas sobre exclu- 


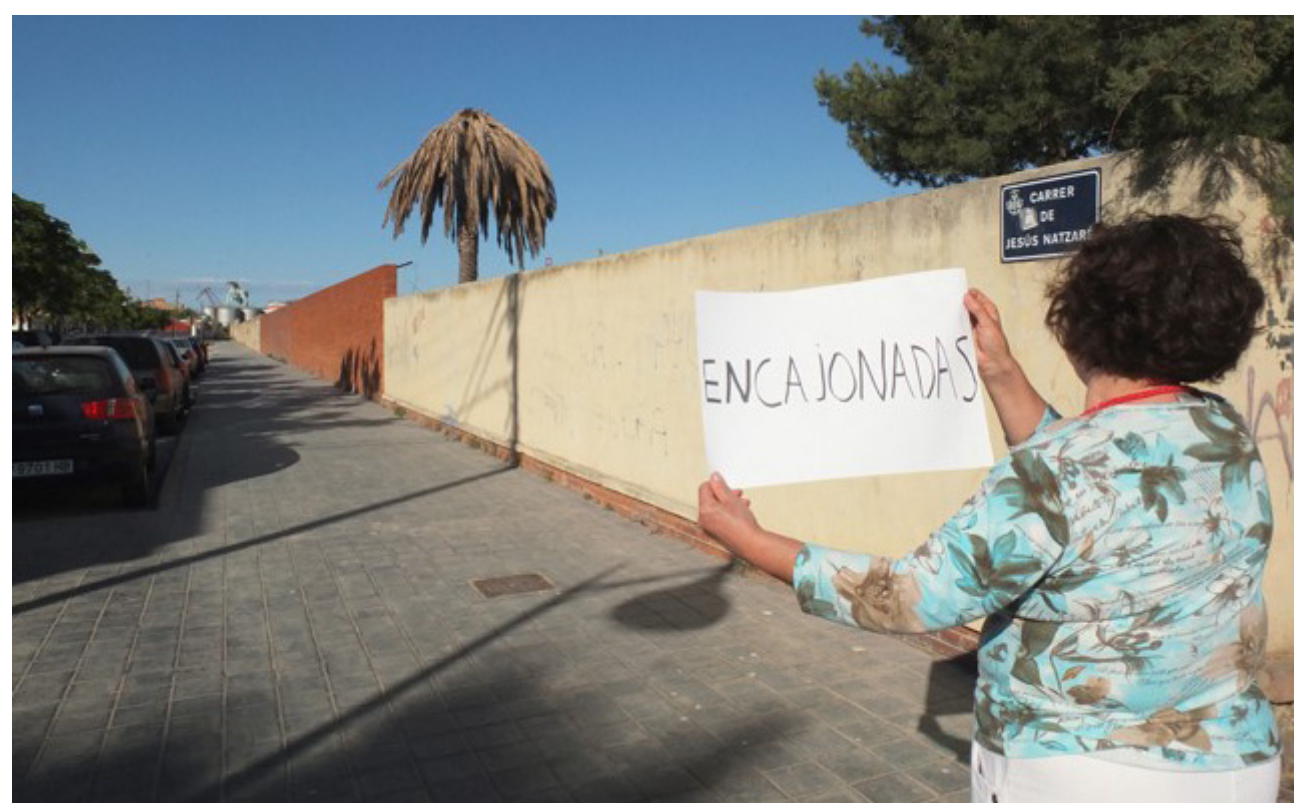

IMAGEN 3.-Sensaciones que provoca el muro que separa de forma tajante Nazaret y el mar.

sucede en sus respectivos conjuntos urbanos. Por un lado, la sensación de abandono, pérdida e indefensión que experimentan sus vecinos y vecinas en todo lo que respecta a la actuación de las administraciones públicas y la dotación de equipamientos y servicios públicos. Por otro, las tendencias evolutivas de las redes interpersonales y de la participación asociativa, que se debilitan y adelgazan a medida que se consolidan los procesos sociopolíticos de la transición política. Durante los últimos años del franquismo había en todas estas zonas, Nazaret incluida, un movimiento vecinal muy activo que alimentaba pautas de solidaridad, confianza y reciprocidad muy sólidas y eficaces; en contraste, en la década siguiente (años ochenta) la lucha vecinal se ralentiza, al tiempo que las redes interpersonales se descarnan y problematizan, al experimentar las dramáticas consecuencias del paro, la droga y el aumento de la delincuencia.

Pero el paralelismo entre Nazaret y los referidos barrios se quiebra en la década de los noventa, momento en que el área que nos ocupa experimenta una tendencia divergente. Así, mientras que en el resto de barrios no se aprecia ninguna recuperación significativa del tejido asociativo, el de Nazaret se redensifica en un contexto atravesado por el conflicto. A mi entender, esta variabilidad guarda estrecha relación con la incidencia a nivel local de esos 'vectores de diversidad' mencionados por Díaz Orueta (2012), entre los que se cuentan la composición socioeconómica específica de cada

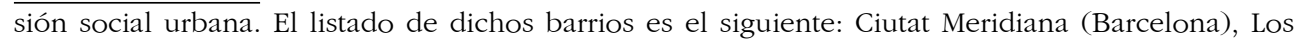
Rosales (Madrid), Otxarkoaga (Bilbao), Espinardo-Espíritu Santo (Murcia) y Tres Barrios-Los Pajaritos (Sevilla). 
zona, la consistencia del tejido asociativo, el impacto de las políticas urbanas y las formas de relación con la Administración. El peso diferencial de dichos vectores en cada espacio barrial puede favorecer, o por el contrario inhibir, el surgimiento de movimientos organizados en defensa de los derechos vulnerados o denegados por las políticas públicas, o el desarrollo de proyectos colectivos para la recuperación de un barrio o de toda la ciudad.

En este orden de cosas, el caso de Nazaret, al igual que el de los otros Poblados Marítimos de Valencia, entre los que destaca el Cabanyal, puede ser tomado como ejemplo paradigmático del potencial participativo que acumulan las periferias urbanas y también del alcance de sus protestas. Aquí, el impacto negativo de las políticas urbanas unido al talante poco —o nada- participativo y conciliador del gobierno municipal del Partido Popular ${ }^{22}$, han actuado conjuntamente para activar el conflicto y dinamizar la trama asociativa vecinal. En los referidos barrios se hallan inscritas las tendencias emergentes de los actuales movimientos urbanos: sus movimientos vecinales no sólo han experimentado profundos cambios en sus formas organizativas y discursivas, en sus modos de relacionarse con los otros agentes sociales que también actúan sobre el territorio y en las estrategias que dirigen su participación activa en la ciudad, sino que han incrementado notablemente y a todos los niveles (local, estatal e incluso internacional) su protagonismo y reconocimiento social. Un movimiento vecinal dinámico y propositivo cuya actividad ha frenado la expansión de la marginalidad en sus barrios respectivos.

Nazaret cuenta en la actualidad con un importante tejido asociativo ${ }^{23}$ en cuya evolución cabe distinguir diversas etapas. El motor que lo fomenta surge a principios de los años setenta del pasado siglo, cuando un grupo de vecinos y de recién llegados al barrio, comprometidos con la izquierda obrerista y el activismo cristiano, comienzan a organizar el vecindario y a sentar las bases de una asociación de vecinos (AA.VV.). En esta primera etapa la Asociación, de marcado carácter asambleario, batalla para lograr dotaciones básicas en infraestructuras y servicios (apertura del nuevo consultorio, alumbrado, asfaltado, alcantarillado, red de agua potable para todos, saneamiento del río y cubrimiento de acequias, parques públicos, transporte escolar gratuito, tasa justa de la basura, etcétera). Una de sus primeras luchas afecta a la propiedad de las parcelas edificadas en la zona marítimo-terrestre del barrio, esto es, en los terrenos de playa que el mar había ido dejando con las sucesivas ampliaciones del puerto durante la primera mitad del XX y que fueron ocupados por la fuerte inmigra-

${ }^{22}$ El Partido Popular ha gobernado ininterrumpidamente los destinos de la ciudad de Valencia entre los años 1991 y mediados de 2015.

${ }^{23}$ En lo que a continuación presento me baso en la información procedente de dos entrevistas realizadas a dos dirigentes vecinales, así como de los blogs y webs directamente relacionados con Nazaret: el de la Associació de Veïns $i$ Veïnes de Natzaret (http://avvnatzaret.blogspot.com.es/), el de una joven vecina del barrio (http://val6ntina.blogspot.com.es/) y el de la Asociación Centre de Música $i$ Dansa Natzaret (http://www.centremusicanatzaret.es/). Sin pretender ser exhaustivos, además de las asociaciones mencionadas, Nazaret cuenta en la actualidad y para poco más de 6.000 habitantes, con dos asociaciones de vecinos, una asociación musical (el Centre de Música i Dansa Natzaret), una asociación de Mujeres (Grup de Dones), varias AMPAS, un Club de Jubilados, diversas Peñas Taurinas, dos Comisiones Falleras (Falla Major-Moraira, Falla Aras de Alpuente-Castel de Pop) y cuatro cofradías (del Santísimo Cristo de Nazaret, de la Marededéu, de Sant Roc y de Sant Josep). 
ción de postguerra. La cuestión es que la propiedad de esa zona correspondía al Ayuntamiento ${ }^{24}$, con lo que la gente que había construido allí su vivienda era propietaria del volumen construido, pero no del suelo. La asociación vecinal luchó mucho por la regularización de esos terrenos a favor de la gente que los ocupaba, cosa que al final consiguieron.

Los años ochenta fueron en general testigos del trasvase muchos de los esfuerzos vecinales a la maquinaria de los partidos políticos y a su quehacer institucional. En Natzaret también se hizo sentir el bajón de la participación vecinal, que dejó de ser masiva. No obstante, la AA.VV. prosiguió su labor desarrollando numerosas iniciativas para la creación de servicios y de espacios socioculturales, contando con la cooperación y buen entendimiento de un grupo de profesionales y técnicos de la Administración que trabajaban en el barrio ${ }^{25}$. Otras iniciativas tenían como objetivo propiciar la interacción y solidaridad vecinal y prevenir la delincuencia juvenil, rebajando al mismo tiempo la creciente tensión entre los colectivos payo y gitano del barrio ${ }^{26}$.

A principios de los noventa la Asociación se halla inmersa en un proceso de profunda reflexión acerca del trabajo comunitario, preocupación presidida por una conciencia cada vez más clara que ninguna organización puede por sí sola representar los intereses de todos. Deciden entonces poner en marcha una serie de intervenciones sobre tres sectores que consideran estratégicos: las mujeres, los jóvenes y los ancianos. Para abordar esta tarea contactan con diversos colectivos de profesionales para que, tras realizar los pertinentes estudios, les asesoren y orienten ${ }^{27}$. Pero avanzar en estas tareas no le será fácil porque por la misma época estalla un conflicto grave que tiene como detonante el derribo por parte del Ayuntamiento de las Casitas de Papel, convertidas en un gueto de narcotraficantes, y el ulterior realojo dentro del barrio de algunos de sus moradores, casi veinte familias gitanas consideradas "limpias" por los

${ }^{24}$ En 1939 el Estado cede por segunda vez al Ayuntamiento de Valencia los terrenos que el mar dejaba al retirarse por efecto de las obras del puerto. Como enfatiza Juan Castaño, "junto a la relación con el Puerto, Natzaret está marcado por la procedencia de su derecho de propiedad. Propiedad que nace de terrenos ganados al mar, es decir, sin propietario inicial, y de la construcción libre sobre los mismos, de las personas que en ellos necesitan ubicar sus viviendas. Personas generalmente faltas de recursos, aunque sea clandestinamente" (1995: 12).

${ }^{25}$ En este orden de cosas destaca la obtención del solar para el Centro Cívico y la posterior construcción del mismo, el Club de jubilados, el Equipo de Servicios Sociales, el nuevo Centro de Atención Primaria, la Escuela de Personas Adultas y la Biblioteca. En lo que respecta la creación de plataformas de tipo cultural, organizativo y lúdico cabe citar, entre otras, el periódico Natzaret, Ràdio Natzaret, el Grup de dones de Natzaret y el Centre de Música $i$ Dansa. En la línea de extender la participación al máximo de personas y de entidades para la mejora del barrio, la Asociación abre el espacio de sus comisiones de trabajo promoviendo distintas coordinadoras inter-organizativas, como las que representan la Comisión de vecinos, colectivos gitanos y Fallas; la Comisión gestora del periódico "Natzaret”; la Comisión de cultura de Nazaret; la Comisión de deportes del barrio; o la Coordinadora de educación.

${ }^{26}$ Esa es la finalidad, respectivamente, de las "Semanas de Cultura y Convivencia" y de la Asociación Juvenil Pebrella,

${ }^{27}$ En el caso de las mujeres se realizó el estudio y la publicación correspondiente (GRICN 1992); en lo que atañe a los jóvenes el estudio dio lugar a un Informe no publicado (Colectivo IOE 1997). Ambos trabajos contaron con el asesoramiento del sociólogo Marco Marchioni, experto en desarrollo comunitario. No tenemos noticias de si llegó o no a ejecutarse la investigación sobre los mayores del barrio. 
conocedores y expertos. A partir de este momento la cuestión se complica: se acusa a la A.V. de favorecer a la población gitana ${ }^{28}$, razón por la cual las relaciones entre los vecinos se tensan al máximo. El resultado es una fuerte división del vecindario, la aparición de una segunda asociación de vecinos (la Asociación de Vecinos Nazaret Unido) y el debilitamiento del liderazgo de la A.V. originaria, que deja de ser 'la' organización por excelencia del barrio para convertirse una asociación más.

Pero ni el conflicto ni sus secuelas paralizan el quehacer de esta Asociación que por el camino transforma su nombre para pasar a llamarse Associació de Veïns i Veïnes de Natzaret. Tampoco se quiebran sus maneras de pensar y hacer; antes por el contrario, en las décadas siguientes consolida la orientación y las líneas de trabajo en las que ya estaba embarcada. Por un lado, continúa impulsando la participación y el trabajo conjunto de las asociaciones y organismos presentes en el barrio, uno de cuyos frutos es una plataforma - la Coordinadora del barrio- que reúne a todas las organizaciones y entidades de Nazaret. Por otro, sigue encabezando la lucha por la dignidad del barrio y de las personas que viven en él. Prosigue por tanto con sus demandas de mejora en las dotaciones y servicios del barrio $^{29}$, al tiempo que multiplica sus acciones reivindicativas contra los agravios y desmanes que, a su entender, lleva años perpetrando el consistorio municipal ${ }^{30}$. En este campo la lucha de la AA.VV no se realiza en solitario sino que la acomete mancomunadamente con organizaciones de otros barrios, en especial de los Poblados Marítimos, con las que ha creado la plataforma El Litoral per al Poble (PELPAP) ${ }^{31}$, cuyos objetivos sobrepasan las fronteras barriales hasta abarcar toda la fachada litoral de la ciudad.

Conviene ahora traer a colación aquellos otros 'vectores de diversidad' aludidos páginas atrás que, junto con el mencionado, inciden en la diversidad evolutiva de los barrios periféricos: el impacto de las políticas urbanas y las formas de relación con la Administración. La incidencia de estos últimos en Nazaret y en el resto de barrios del distrito marítimo aviva la participación vecinal y dinamiza el tejido asociativo, trabajando conjuntamente hasta hacer de contrapeso de ciertos factores estructurales (bajas rentas, envejecimiento, altos niveles de inmigración, etc.) que empujan hacia la exclusión social.

${ }^{28}$ La Asociación de vecinos con la que he trabajado achaca esta complicación a los intereses políticos de la derecha valenciana, concretamente al partido regionalista Unió Valenciana (UV), que "intencionadamente enturbiaron con malas interpretaciones, bulos y calumnias esa situación con la finalidad concreta de movilizar al vecindario contra la Asociación de Vecinos de Nazaret, acción que después de diversos intentos fallidos cuajó en la creación de una nueva asociación de vecinos que paradójicamente se denominó "Nazaret Unido" (http://avvnatzaret.blogspot.com.es/).

${ }^{29}$ En lo que va de siglo, en Nazaret se ha construido y puesto en funcionamiento un nuevo Centro de Salud y también se ha remodelado el Polideportivo municipal.

${ }^{30}$ De esta actividad da noticia el blog de la asociación, que comienza su andadura en octubre de 2012" (http://avvnatzaret.blogspot.com.es/).

${ }^{31}$ En septiembre de 2013, siete asociaciones vecinales (Amics de la Malva, Cabanyal-Canyamelar, Grau-Port, Vilanova del Grau y Natzaret, a las que se suman otros dos enraizadas al norte de la frontera de la ciudad) sacan a la luz un documento fundacional, el Manifest de les Associacions de Veïns del Litoral de València, en el que critican "la visión economicista" que ha marcado los tiempos de la planificación del litoral de la ciudad, subrayando las consecuencias negativas que han provocado dos órdenes de intervenciones: la ampliación del puerto para el caso concreto de las playas y los territorios del sur; y los grandes eventos, "efímeros y ruinosos", que han hipotecado el conjunto de la fachada marítima. 
En relación a las políticas urbanas aplicadas durante las dos últimas décadas por el gobierno municipal en los barrios marítimos de Valencia cabe decir que sus efectos presentan una doble cara: a la dualidad socioespacial preexistente (playa/franja interior), se ha añadido otro eje de diferenciación que discurre perpendicular al mar, separando social y funcionalmente dos zonas. En el norte de dicho eje se consolidan las funciones residencial, turística y de ocio, mientras que los territorios del sur, donde se sitúa Nazaret, se supeditan a la actividad portuaria. Los paradójicos efectos de los desarrollos del urbanismo neoliberal muestran en esta franja marítima todos sus oropeles y miserias: al tiempo que los grandes eventos y los grandes proyectos alimentan la gentrificación, el turismo de élite y el glamour cosmopolita, aumentan la fragmentación socioespacial y la precariedad y se afianzan los espacios del miedo; por último, en aras de la supremacía del Puerto de Valencia y de su competitividad, se sacrifica el bienestar de los Poblados Marítimos y se hipoteca el futuro del litoral (Cucó 2013a, 2013b, 2014).

Lo expuesto hasta aquí permite entender por otro lado que las relaciones de estos barrios con la Administración local disten de ser armoniosas. Ocurre a menudo que, ante tanto desaguisado, parte del vecindario muestra públicamente su malestar protestando. Sus resistencias y combates no son nuevos, pero se acrecientan con el impacto de la crisis, que ha agravado los problemas de la ciudad, dejando al descubierto las deficiencias (enormes) de la gestión municipal y un déficit abrumador. En imaginarios ejercicios de advocacy, las organizaciones vecinales se oponen a los proyectos y actuaciones municipales que consideran lesivos para sus intereses y/o para bien colectivo, combinando las acciones administrativas y judiciales con otras de mayor impacto ciudadano y mediático (Sorribes 2001; Cucó 2009 y 2014; Santamarina 2014). A menudo realizan demandas en solitario, sobre todo cuando los problemas afectan solamente a su barrio ${ }^{32}$, pero también trabajan en red con otras asociaciones para planear estrategias y proyectos conjuntos de más hondo calado. Este cúmulo de iniciativas y actuaciones han obstaculizado que la balanza de la evolución del barrio, de Nazaret pero también de los otros Poblados Marítimos, se inclinara hacia la marginación y la exclusión social. Como advierte en su blog la A.V. de Nazaret, en esa labor estuvieron comprometidos en el pasado y continúan estándolo en la actualidad.

Y seguiremos ciertamente —en el aspecto territorial— frente a la megalómana actitud de nuestras administraciones local y autonómica (Copa América, Fórmula 1...). O a la persistente amenaza del Puerto (jsiempre el puerto!...), persiguiendo la integración de Natzaret

\footnotetext{
${ }^{32}$ Algunas demandas son de hondo calado y afectan al Plan General de Ordenación Urbana de Valencia, caso de la alegación presentada por la A.V. de Nazaret en el nuevo proceso de exposición al público de la revisión del PGOU, que concluyó 24 de febrero de 2015, en la que instaba al Ayuntamiento a modificar el circuito de Fórmula 1, actualmente sin uso. Según la documentación que manejan los vecinos, dicho circuito invade una zona verde, concretamente la del tramo final del Jardín del Turia; a este respecto los vecinos reclaman que se saquen los viales de la zona verde para adecuarlos así a la legalidad urbanística vigente y se replantee en paralelo todo el PAI del Grao. También se reivindican mejoras en la red de transportes públicos, tal y como ocurre en Nazaret, cuyo vecindario demanda que se ponga en servicio una línea de metro-tranvía cuyas infraestructuras están sin acabar desde hace años (noticia en el blog de la A.V. de Nazaret de 07/03/2015).
} 
en la ciudad y los Poblados Marítimos (¡a por el tranvía y el enterramiento de las vías!), presionando por una vivienda asequible para la juventud; y en el aspecto social: trabajando la integración de los inmigrantes en tanto que nuevos vecinos, buscando las grietas del narcotráfico en el barrio, alertando sobre la problemática educativa, combatiendo el desempleo y el bajo nivel de renta del barrio, empeñándonos en conseguir un barrio más limpio, agradable y confortable para todos ${ }^{33}$.

\section{CONCLUSIONES}

A lo largo de estas páginas hemos observado a Nazaret, un barrio periférico de la Valencia litoral, desde tres perspectivas complementarias: la primera ofrece una mirada sincrónica de su estructura socioespacial actual; la segunda contextualiza diacrónica y procesualmente los cambios que experimenta en el transcurso del último siglo; la tercera aborda las percepciones e imágenes que caracterizan al barrio así como los rasgos, actividad e incidencia de su tejido asociativo. En este recorrido se ha focalizado el comportamiento e influencia mutua de una serie de factores entre los que destacan, por un lado, los impactos del puerto y de las políticas urbanas, y la composición socioeconómica del barrio; por otro, la consistencia de su tejido asociativo y la relación que mantiene con la administración. Mientras los tres primeros ítems favorecen la extensión de la precariedad y la vulnerabilidad social, impeliendo al barrio hacia la marginación y la exclusión, los segundos, encabezados por el fuerte dinamismo de su asociación de vecinos y el enfrentamiento que mantiene con el consistorio municipal, neutralizan la anterior tendencia, obstaculizando el tránsito de barrio marginado a barrio marginal.

El impacto del puerto sobre Nazaret aparece como una constante durante más de un siglo. Durante finales del XIX y primer tercio del XX su expansión corre pareja con el auge económico valenciano, lo que incide directamente sobre el barrio para romper su aislamiento y dinamizar su estructura socioeconómica. Los años ochenta y noventa del pasado siglo representan otro momento decisivo en la relación Nazaretpuerto, durante el que el barrio pierde su playa, su conexión directa con el mar y una parte importante de su huerta.

Estos desarrollos han contado y continúan contando con la complicidad y el beneplácito de los sucesivos gobiernos municipales de Valencia, del pasado y del presente —al menos hasta mediados del 2015-, cuyas políticas urbanas han contribuido decisivamente al menoscabo de la calidad de vida y del medioambiente del barrio. Durante el franquismo, el crecimiento incesante del puerto combinado con el desarrollismo sin freno de los años sesenta favoreció un proceso creciente de deterioro y aislamiento geográfico, al que se suma la escasez de infraestructuras y de servicios básicos. Por su parte, los años noventa representan la entronización en Valencia de las políticas urbanas de corte neoliberal, que impactan sobre la trama sociourbana de la ciudad modificándola en un doble sentido: aumento de la desigualdad socioespacial y extensión de la precariedad. En el caso concreto de Nazaret, la huella de esas políticas no sólo refuerza los estigmas que pesan sobre su imaginario sino que sacrifica su bienestar e hipoteca su futuro.

\footnotetext{
${ }^{33}$ http://avvnatzaret.blogspot.com.es/
} 
Este microtapiz de precariedad y vulnerabilidad socioespacial constituye la base sobre la que se asienta la relación del barrio con el gobierno municipal y también la consistencia de su tejido asociativo. Aquí, el impacto negativo de las políticas urbanas unido al talante poco $-\mathrm{O}$ nada- participativo y conciliador del gobierno municipal del PP han actuado conjuntamente para activar el conflicto y dinamizar la trama asociativa vecinal, en el que juega un papel decisivo la Asociación de vecinos nacida en las postrimerías del franquismo. Desde entonces, pese a que las luchas y sus secuelas han afectado significativamente a esta organización, no se han quebrantado sus líneas prioritarias de pensamiento y de praxis: ampliar el tejido asociativo del barrio e impulsar el surgimiento y trabajo conjunto de las asociaciones y organismos presentes en él; continuar con sus demandas de mejora en las dotaciones y servicios del barrio multiplicando al mismo tiempo sus acciones reivindicativas. Asimismo, los resultados de estos objetivos y luchas han permitido desactivar algunos de los 'efectos de barrio' (negativos), pues han favorecido el acceso de la población a bienes como el espacio público, los equipamientos y los servicios públicos de calidad, colaborando al mismo tiempo a la consolidación de una trama asociativa sólida y bastante diversificada. A este respecto cabe señalar por último que las aspiraciones de la Associació de Veïns $i$ Veïnes de Natzaret tienen un notable cariz proactivo: además del propio barrio, pretenden transformar todo el frente litoral y con él el conjunto de la ciudad, unos objetivos por los que trabajan en red a nivel suprabarrial y que aparecen plasmados en un manifiesto público.

\section{BIBLIOGRAFÍA CITADA}

Alguacil Gómez, Julio, Javier Camacho Gutiérrez y Agustín Hernández Ajá. 2014. "La vulnerabilidad urbana en España. Identificación y evolución de los barrios vulnerables". Empiria: Revista de Metodología de Ciencias Sociales, 27: 73-94.

Anguelovski, Isabelle. 2013. "From Environmental Trauma to Safe Haven: Place Attachment and Place Remaking in Three Marginalized Neighborhoods of Barcelona, Boston, and Havana". City $\mathcal{E}$ Community 12(3):211-237.

Arqués, Ramón. 2011. "La Història de Natzaret d'un cop d'ull", en VV.AA., 50 anys fent falla: 38189. València: Falla Major-Moraira de Natzaret.

Bauder, Harald. 2002. "Neighbourhood Effects and Cultural Exclusion". Urban Studies 39 (1): 85-93.

Buck, Nick. 2001. "Identifying neighborhood effects on social exclusión". Urban Studies 38 (12): 2251-2275.

Blanco, Ismael, Sonia Fleury y Joan Subirats. 2012. "Nuevas miradas sobre viejos problemas. Periferias urbanas y transformación social". Gestión y Política Pública, volumen temático 2012: 3-40.

Cabrejas, Mara y Ernest García. 1997. València, l'Albufera, l'Horta: medi ambient $i$ canvi social. València: PUV.

Cal Barredo, Ma Luz y Pedro Martínez Monje. 2009. "Barrios con privación y exclusión social. Estructura de oportunidades y exclusión social". Zainak 32: 877-897.

Castaño, Juan. 1995. Nazaret y sus calles. Valencia: Asociación de Vecinos de Nazaret-Generalitat Valenciana.

Colectivo de estudios por la autonomía obrera. 1977. Luchas autónomas en la transición democrática. Tomo II. A remolque de la reforma.12-Nov.-76/15-Junio-77. Bilbao: Zero S.A.

Colectivo Ioé. 1997. Jóvenes del barrio de Nazaret (Valencia). Informe elaborado a demanda de la AA.VV. de Natzaret (València). Documento en .pdf cedido por la A.V.

Cort, Jaume. 1995. "Apuntes histórico-urbanísticos de Nazaret", en Juan Castaño, Nazaret y sus calles: 11-16. Valencia: A.V. de Natzaret-Generalitat Valenciana.

Cucó, Josepa. 2009. "Los movimientos urbanos en la ciudad de Valencia”. Zainak 31: 529-549. 
Cucó, Josepa. 2013a. "Poniendo a Valencia en el mapa global. Políticas, desarrollos urbanos y narrativas sobre la ciudad", en Josepa Cucó Giner (ed.), Metamorfosis urbanas. Ciudades españolas en la dinámica global: 157-180. Barcelona: Icaria.

Cucó, Josepa. 2013b. "Éxitos y perversiones en las fórmulas neoliberales. Los contrastes entre Barcelona, Bilbao y Valencia", en Josepa Cucó (dir.), La ciudad pervertida. Una mirada sobre la Valencia global: 213-232. Barcelona: Anthropos.

Cucó, Josepa. 2014. "En aras de la globalización neoliberal: los barrios del water front de Valencia". Sociologia urbana e rurale 104: 12-28.

Cucó, Josepa (ed.) 2013a. Metamorfosis urbanas. Ciudades españolas en la dinámica global. Barcelona: Icaria.

Cucó, Josepa (dir.) 2013b. La ciudad pervertida. Una mirada sobre la Valencia global. Barcelona: Anthropos.

Davis, Mike. 2001. Más allá de Blade Runner. Control urbano: la ecología del miedo. Bilbao: Virus Editorial.

Díaz de Orueta, Fernando. 2012. "Periferias urbanas y reconfiguración de las políticas urbanas en España”. Gestión y Política Pública, volumen temático 2012: 41-81.

Füredi, Frank. 2007. The Culture of Fear Revisited: Risk-Taking and the Morality of Low Expectation. Londres: Continuum.

García, Ernest (coord.) 1999. Els valors de la punta: 18 arguments en defensa de l'Horta. València: PUV.

García Pilán, Pedro y Miquel Ruiz Torres, (2013). "Degradación, espectacularización y espacios del miedo: el Cabanyal", en Josepa Cucó (ed.), Metamorfosis urbanas. Ciudades españolas en la dinámica global: 353-376. Barcelona: Icaria.

Glassner, Barry. 1999. The culture of Fear. Nueva York: Basic Books.

GRICN (Grupo de Intervención Comunitaria de Nazaret). 1992. La mujer en el barrio de Nazaret. Valencia: Generalitat Valenciana.

Houart, Noémie y Pauline Annerel. 2011. "Des 'effets de quartier' à la politique de la ville. Perspectives onternationales". Note d'Analyse du Centre d'Analyse Strategique 24. Disponible en <http:// www.strategie.gouv.fr/content/des-effets-de-quartier-la-politique-de-la-ville-perspectivesinternationales-note-danalyse-2>. Fecha de acceso: 02 abril 2016.

Kearns, Ade y Michael Parkinson. 2001. "The significance of neighbourhood". Urban Studies 38 (12): 2103-2110.

Marcuse, Peter y Ronald Van Kempen (eds.). 1999. "Introduction", en Globalizing cities. A new spatial order?: 1-21. Oxford: Blackwell Publishers.

Martínez Monje, Pedro. 2006. Pobreza urbana y exclusión espacial en el Área Metropolitana de Bilbao, 1990-2000. Tesis doctoral no publicada.

Massey, Douglas S. y Nancy A. Denton. 1993. American Apartheid. Cambridge, MA.: Harvard University Press.

Murie, Alan y Sako Musterd. 2004. "Social exclusion and oportunity structures in european cities and neighbourhoods". Urban Studies 41 (8): 1441-1459.

Musterd, Sako. 2008. "Diverse poverty neighbourhoods. Reflections on Urban Outcasts". City 12 (1): 107-114.

Musterd, Sako, Alan Murie y Christian Kesteloot (eds.) 2006. Neighbourboods of Powerty: Urban Social Exclusion and Integration Comparison. Londres: Palgrave Mcmillan.

Raulin, Anne. 2001. Anthropologie urbaine. París: Armand Colin.

Romero, Joan y Miquel Francés (eds.) 2012. La Huerta de Valencia. València: PUV.

Ruiz Torres, Miquel y Pedro García Pilán. 2013. "Disolución del lugar y espacios del miedo en el Cabanyal", en Josepa Cucó (dir.), La ciudad pervertida. Una mirada sobre la Valencia global: 67-94. Barcelona: Anthropos.

Sanchis Pallarés, Antonio. 2011. Historia de la Malvarrosa. Nacida del agua. Alzira: Germania.

Santamarina, Beatriz (dir.) 2009. Llàgrimes vora mar. Guerra, postguerra i riuada al Cabanyal (19361957) a través de la memoria. València: PUV.

Santamarina, Beatriz. 2014. "El oficio de la resistencia. Salvem y Viu al Cabanyal como formas de contención del urbanismo neoliberal”. Revista de Dialectología y Tradiciones populares LXIX (2): 205-326. 
Sorribes, Josep. 2001. "El malestar urbà a València: a propòsit dels 'salvem'. Mètode 31. Disponible en <http://metode.cat/Revistes/Monografics/Existeix-la-ciutat-somiada/El-malestar-urba-a-Valenciaa-proposit-dels-salvem>. Fecha de acceso: 02 abril 2016.

Torres Pérez, Francisco y Pedro García Pilán. 2013. «La ciudad ocultada. Desigualdad y precarización en la Valencia global", en Josepa Cucó (dir.), La ciudad pervertida. Una mirada sobre la Valencia global: 191-212. Barcelona: Anthropos.

Vallet, Louis-André. 2005. "La mesure des effets de quartier/voisinage: un objet importants et difficile à la croisée des sciences sociales". Revue économique 56(2): 363-369.

Van Ham, Maarten, David Manley, Nick Bailey, Ludi Simpson y Duncan Maclennan (eds.) 2012. Neighbourbood Effects Research: New Perspectives. Dordrecht: Springuer.

VV.AA. 1991. Barrio de Nazaret. Propuestas 92. València: Associació de Veïns de Natzaret - Federació Associacions de Veïns de la Comunitat Valenciana.

Wacquant, Loïc. 2001. Parias urbanos. Marginalidad en la ciudad a comienzos del milenio. Buenos Aires: Manantial.

Wacquant, Loïc. 2007. Los condenados de la ciudad. Gueto, periferias y Estado. Buenos Aires: Siglo XXI.

Wilson, William J. 1987. The Truly Disadvantaged; The Inner City, the Underclass, and Public Policy. Chicago: University of Chicago Press

Fecha de recepción: 4 de junio de 2015

Fecha de aprobación: 17 de enero de 2016 